\title{
Parameters analysis for a sustainable management of solid waste in university buildings
}

\author{
Marco Ragazzi ${ }^{1 *}$, Elena Cristina Rada $^{2}$, Alessandro Abbà ${ }^{3}$ and Marco Schiavon ${ }^{1}$ \\ ${ }^{1}$ University of Trento, Department of Civil, Environmental and Mechanical Engineering, Via Mesiano \\ 77, Trento, Italy \\ ${ }^{2}$ Insubria University of Varese, Department of Theoretical and Applied Sciences, Via G.B. Vico, 46, \\ Varese, Italy \\ ${ }^{3}$ University of Brescia, Department of Civil, Environmental, Architectural Engineering, and \\ Mathematics, Via Branze 43, Brescia, Italy
}

\begin{abstract}
Educational institutions and, specifically, university campuses are large energy consumers and waste producers. The impact of university campuses on the local waste management increases with decreasing the size of the city/town where universities are located. Following the growing interest of the scientific community on the research for strategies to improve the environmental sustainability of educational institutions, this paper aims at proposing specific parameters to 1) measure the performance of university buildings in waste management, 2) detect anomalous situations that require improvements and 3) implement ameliorative actions. Specifically, parameters like the per-capita or surface-specific waste generation could help identifying the structures that may require primary interventions. With reference to the case of a medium-size university, the paper points out the advantages of the punctual tariff system for waste management adopted by the local utility company and critically analyses its weak points. Overall, this system offers great opportunities for improving waste management and for cost savings, but requires careful management policies by public institutions.
\end{abstract}

\section{Introduction}

The importance of educational institutions as deliverers of "green" virtuous behaviours is demonstrated by the recent growing interest in university campuses and in their research for sustainable strategies in terms of energy efficiency [1,2], mobility [3-5], waste management [6-9] and, in general, carbon footprint [10-11]. The recent introduction of green university rankings is expected to stimulate further efforts in this field [12-14]. Implementing actions towards sustainable waste management in an educational institution, in addition to reducing the production of residual Municipal Solid Waste (RMSW) from a large-scale user, is expected to positively influence the society, since students have the power to instil the

\footnotetext{
*Corresponding author: marco.ragazzi@unitn.it
} 
virtuous behaviours learnt at school/university to their families, friends and to the community [15-16].

The principles of Circular Economy (CE) have been set in 2015 by the European Union starting from the sector of MSW [17]. The issue is not related only to the waste produced at household level: indeed, in urban environments, complex buildings can be significant contributors of RMSW. More in detail, schools and universities play a fundamental role in this sense, since the generation of RMSW by school/university buildings may be considerable higher than the household generation of MSW, especially in small-size urban areas [18]. In fact, in addition to being large consumers of energy [19], complex educational buildings host different types of activities (classes, catering, office work, laboratory activities, public events) that generate recyclable and non-recyclable waste streams.

With regard to this aspect, in Italy the optimization of MSW management in university buildings is part of a network initiative named RUS ("Rete delle Università per lo Sviluppo Sostenibile", i.e. network of universities for sustainable development) [20]. This initiative has showed advantages in the circulation of data and knowhow in order to make Italian universities more sustainable.

The present article focuses on the definition of parameters that can be defined for supporting the decision makers in charge for the management of MSW in the universities. Specifically, the article will point out some advantages and criticalities in the adoption of the punctual tariff in the MSW management. The methodology adopted in the paper consists of a few steps: selection of a case study depending on the way of managing MSW; analysis of the characteristics of selective collection (logistics, risks, economic criteria adopted); zooming on parameters suitable for an easy check of the system; discussion on the advantages and criticalities of the system.

\section{Case study}

The selected case study is an Italian University. The academic community consists of about 14,000 undergraduate and master students, $700 \mathrm{PhD}$ students and postdocs, 1,400 researchers and professors, and 600 administrative employees, for a total amount of about 16,700 people. This university is characterized by a high fractionation of buildings, including departments, research centres, laboratories, administrative buildings and guesthouses, accounting for about 45 buildings displaced around the town where the university is located. Considered that the population of the whole town is 117,417 inhabitants [21], the university community represents potentially $14.2 \%$ of the whole population. The relatively high pressure made by the university in terms of population implies additional pressures at other levels, such as transportation and waste management. The first issue may be exacerbated by the presence of complex terrain or limited road infrastructures, like the present case study. The second issue may be critical if: 1) the percapita or surface-specific production of residual MSW (RMSW) by the university community exceeds the respective RMSW production expected by the remaining population of the town and/or 2) the performance of selective collection by the university community (where active) is worse than the average selective collection rate of the residents. In the present case study, a well-established selective collection system is active in the territory of the municipality of the town. However, it must be considered that, according to internal statistics, about $11 \%$ of students come on daily basis from other municipalities, where the selective collection rules can vary from those of the town where the university is located.

In the study area, a system based on the so-called "punctual tariff" is adopted by the local utility that manages waste collection and treatment. Contrarily to a tax approach, for 
instance based only on the surface of a house and on the number of occupants, the punctual tariff is composed of a fixed cost and of a variable cost. The variable cost is strictly related to the volume of RMSW produced, by mean of a coefficient that may vary among users, depending on several factors (e.g., location, type of user, etc.). Exceeding a minimum volume of RMSW produced by a user (which is set to account for unrealistic "zero waste" production) translates into the application of the coefficient to the excess volume.

In the municipality of the present case study, the quality of source separation streams is regularly checked by the local utility to avoid anomalous behaviours by the users. In public buildings, like in the case of the university considered in this paper, the bins for source separation are chosen and located in the buildings to limit occupational risks during their handling. To this concern, particular attention is put to avoid the introduction of special waste (e.g. from laboratories) into the circuit of MSW. In the present case study, special waste streams follow a dedicated path for their handling and disposal. MSW is separated by the users into three categories: paper and cardboard, light packaging and RMSW. Those categories are collected into dedicated bins with specific colours that identify the type of waste to be collected. Additional bins for the collection of food waste are located at bars, canteens and close to vending machines. Bars also host bins for glass collection. The cleaning staff is in charge to transfer the bins to specific areas located externally to the buildings, and accessible to the local utility for the withdrawal of waste.

\section{Results and discussion}

Fig. 1 presents the comparison between the minimum volume of RMSW set by the local utility and the effective volume invoiced related to all the university buildings of the case study. The total invoiced volume, in this example, is more than three times higher than the minimum, and this may indicate possible anomalies in the management of waste by the personnel of the university, specifically:

- low selective collection rates;

- abusive waste disposal from external users;

- non-optimised control of the external containers by the personnel.

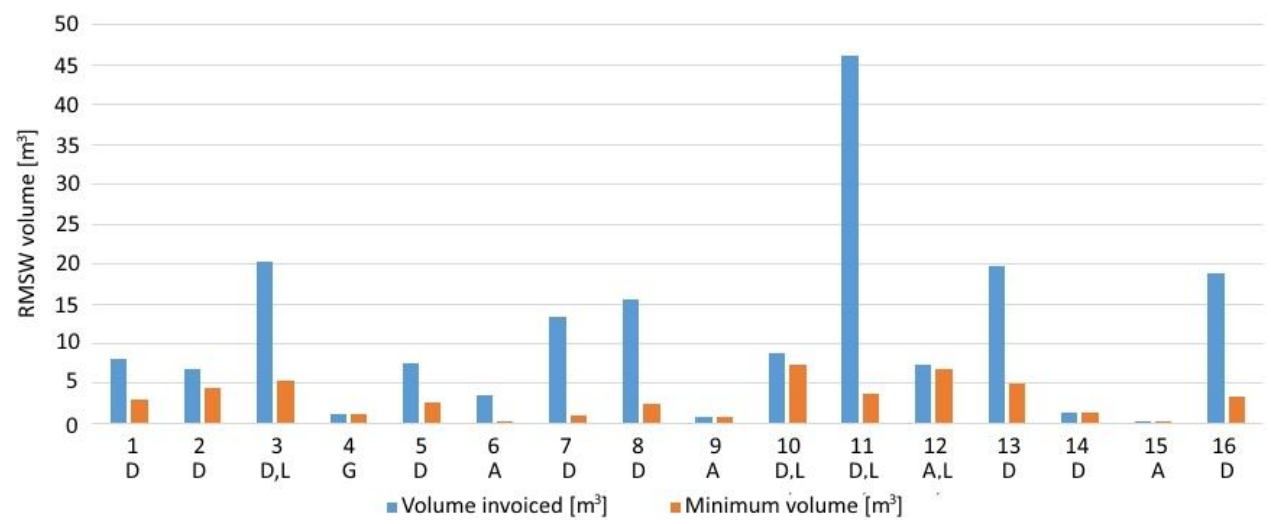

Fig. 1. Differences between the invoiced and minimum volumes of RMSW in 16 buildings of the present case study (A: building with administrative activities; D: building with didactic activities; G: guesthouse; L: laboratories).

Thanks to intensive communication campaigns on selective collection to the academic community, to the detailed level of information on proper selective collection modalities and to the overall high selective collection rate of the province (about 82\%), the first 
hypothesis seems to be not realistic $[22,23]$. The documented episodes of abusive waste disposal from external users give credits to the contribution of this phenomenon on the high difference between minimum and invoiced volume. However, another possible important reason is the non-optimised control of the containers located in the external areas by the personnel of the university. The missing closure of the containers with their specific lock, after the emptying of the bins used in the buildings, involves two criticalities: 1) leaves the containers freely accessible to external users and 2) allows the local utility to empty containers that might not be full. Indeed, the invoicing is not based on the effective volume collected by the vehicles of the local utility managing waste, but on the number of times a container is emptied. This action may occur also when a container is not completely full, if the container is not locked and, thus, accessible to the local utility. Therefore, if the containers are not properly managed, the user will pay more than the effective volume of RMSW produced.

Anomalies in the waste management of single buildings can be easily recognised by looking at the per-capita or surface-specific volume of waste invoiced. Figures 2 and 3 report an example on the use of such parameters and refer to the university buildings in which data on the surface and on the average number of people working/studying are available per single structure. Such parameters could be used to detect the buildings that require priority interventions to improve the management of waste.

Any remarks on the per-capita or surface-specific analysis should consider the context of each structure, since different buildings may be characterised by different levels of waste production. One typical example is represented by laboratories, which normally do not permanently host students, but may generate relatively high amount of RMSW (besides special waste, which follows a dedicated path and will not be considered in this paper). In addition, in the case of buildings with bad performance in terms of RMSW generation, the analysis should always consider the absolute RMSW production: indeed, some buildings with bad performances may be characterised by relatively low waste production, while other structures with better performance may generate much more RMSW and, thus, may require priority interventions.

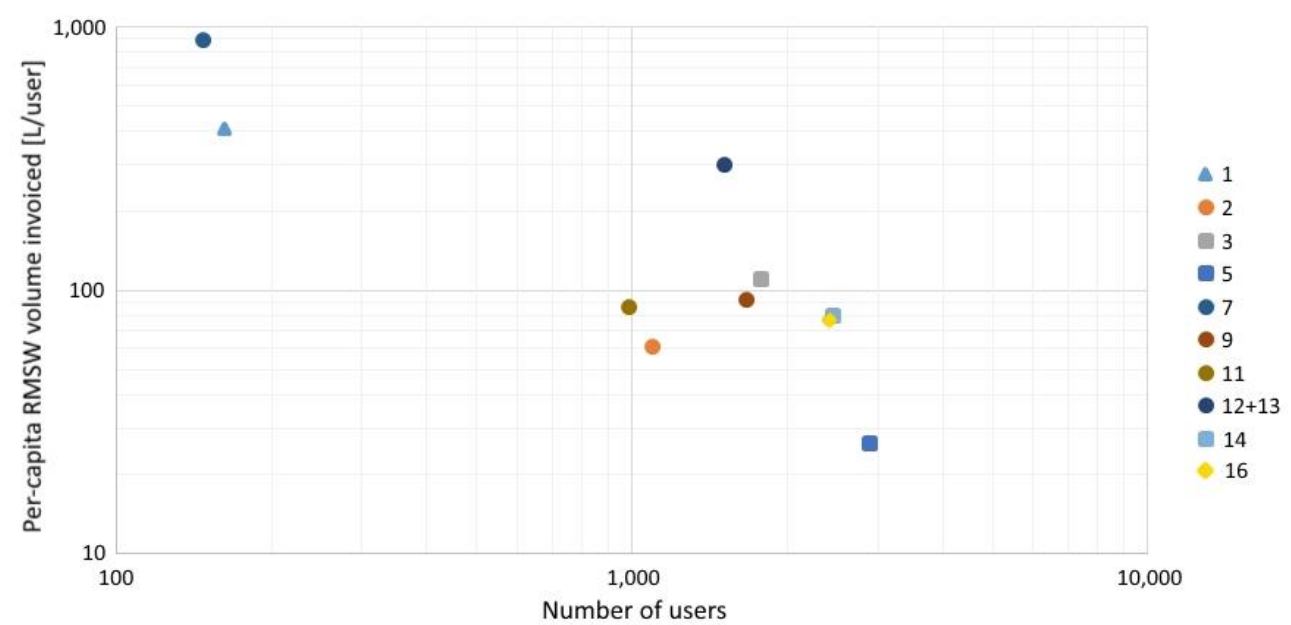

Fig. 2. Example of per-capita analysis of the RMSW volume invoiced in some of the buildings of the present case study, for which information on the average number of users was available. 


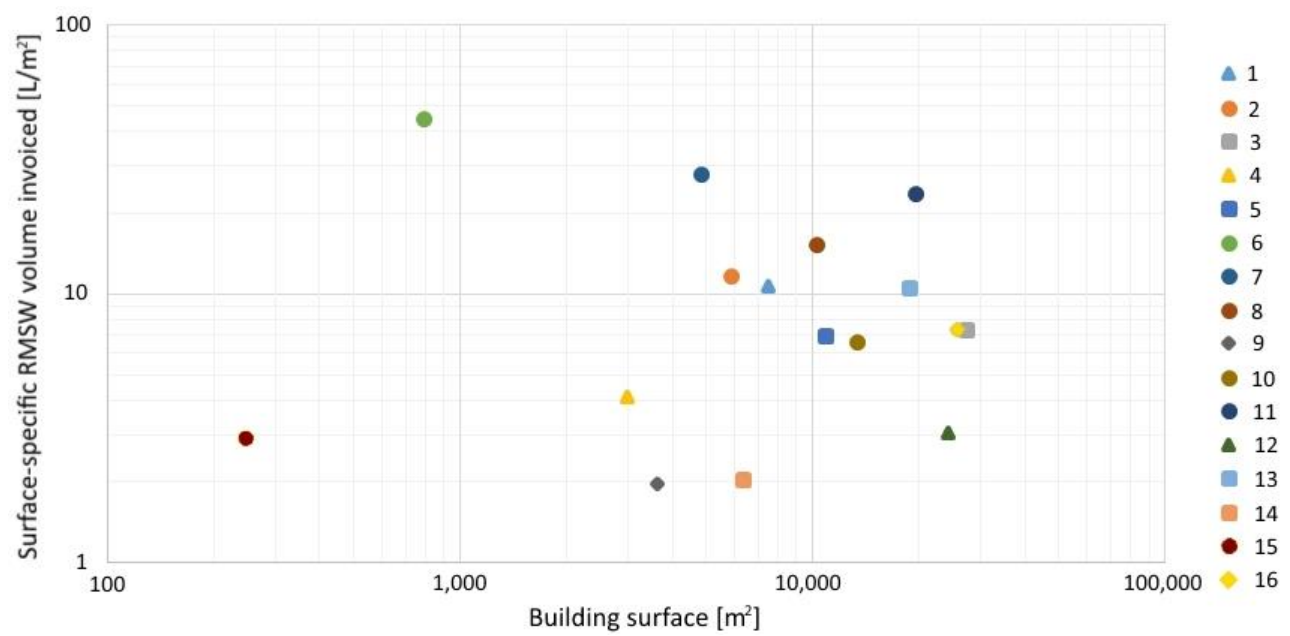

Fig. 3. Example of surface-specific analysis of the RMSW volume invoiced in 16 buildings of the present case study.

The main risk related to the punctual tariff system comes from the possibility that external users throw their waste into containers other than their own ones, in order to pay less. This can especially happen where containers are located in external areas that may become accessible to strangers. The use of parameters like the total volume of RMSW withdrawn by the local utility and indicators like the per-capita or surface-specific RMSW production can help identifying anomalous situations.

\section{Conclusions}

Complex structures, composed of several buildings, may complicate the management of the waste generated and the detection of critical issues in waste management. The adoption of a punctual tariff system for waste allows for an easy and rapid quantification of the RMSW generated. Where a minimum waste threshold volume is considered in the local tariff system, the difference between the invoiced waste volume and the minimum allows obtaining indications on both the performance of a public body or large company in terms of selective collection and the presence of anomalies in the way the waste is internally managed. Parameters like the per-capita or surface-specific waste generation could help identifying the structures that may require primary interventions. The punctual tariff system then represents a great opportunity to improve the waste management of universities and other big organisations, compared to the most common alternative (i.e., forfeit tariff). Since this tariff type rewards users with virtuous behaviours and penalises users with high RMSW generation, such a system stimulates the users to adopt efficient strategies for waste prevention, source separation and optimised waste management, allowing for cost saving at the same time.

\section{References}

1. M. Pritoni, K. Salmon, A. Sanguinetti, J. Morejohn, M. Modera, Energy Build 144, 241-250 (2017)

2. J. Han, E. Lee, H. Cho, Y. Yoon, H. Lee, W. Rhee, Sensors 18, A1605 (2018)

3. S. Azzali, E.A. Sabour, Case Stud Transp Policy 6, 603-612 (2018)

4. A. Dehghanmongabadi, S. Hoşkara, Sustainability 10, 4842 (2018) 
5. L. dell'Olio, R. Cordera, A. Ibeas, R. Barreda, B. Alonso, J.L. Moura, Transp Policy 80, 148-156 (2019)

6. K. Ebrahimi, L. North, J. Yan, Int Conf Geoinform 2017, 8090915 (2017)

7. R. Moreira, T.F. Malheiros, J.F. Alfaro, T.B. Cetrulo, L.V. Ávila, Waste Manag 80, 292-298 (2018)

8. S. Ahmed, C. Byker Shanks, M. Lewis, A. Leitch, C. Spencer, E.M. Smith, D. Hess, Int J Sustain High Educ 19, 1075-1094 (2018)

9. M. Setyowati, A. Kusumawanto, A. Prasetya, J Phys Conf Ser 1022, 012041 (2018)

10. O.J. Robinson, A. Tewkesbury, S. Kemp, I.D. Williams, J Clean Prod 172, 4435-4455 (2018)

11. M. Guerrieri, M. La Gennusa, G. Peri, G. Rizzo, G. Scaccianoce, Renew Sustain Energy Rev 113, 109263 (2019)

12. M. Ragazzi, F. Ghidini, Energy Procedia 119, 111-120 (2017)

13. M. Baricco, A. Tartaglino, P. Gambino, E. Dansero, D. Cottafava, G. Cavaglià, E3S Web Conf 48, 03003 (2018)

14. S.M. Najafian, E. Karamidehkordi, E3S Web Conf 48, 04001 (2018)

15. J.M.F. Mendoza, A. Gallego-Schmid, A. Azapagic, A., J Clean Prod 220, 553-567 (2019)

16. J.B.S.O. de Andrade Guerra, J. Garcia, M. de Andrade Lima, S.B. Barbosa, M.L. Heerdt, I.I Berchin, J Clean Prod 172, 1674-1690 (2018)

17. European Commission, COM(2015) 614 final (2015).

18. E.C. Rada, C. Bresciani, E. Girelli, M. Ragazzi, M. Schiavon, V. Torretta, Sustainability 8, 840 (2016).

19. M. Schiavon, M. Ragazzi, G. Coller, N. Ferronato, V. Torretta, E.C. Rada, WIT Trans Ecol Environ 222, 59-71 (2019)

20. RUS - Rete delle Università per lo Sviluppo Sostenibile. Available on https://sites.google.com/unive.it/rus/home

21. ISTAT Database. Available on http://dati.istat.it

22. Municipality of Trento - Selective collection 2019. Available on https://www.comune.trento.it/Aree-tematiche/Ambiente-e-territorio/Rifiuti-urbani/Gestioneintegrata-rifiuti/Raccolta-differenziata/Risultati-raggiunti/Raccolta-differenziata-2019

23. E.C. Rada, C. Zatelli, P. Mattolin, WIT Trans Ecol Environ 180, 187-197 (2014) 